\title{
Analisis Kerja Rele Overall Diferensial Pada Generator Dan Transformator PLTG Paya Pasir PT. PLN Persero
}

\author{
Surya Hardi, Muhammad Adam, Io Arisandy \\ Program Studi Teknik Elektro, Fakultas Teknik \\ Universitas Muhammadiyah Sumatera Utara (UMSU) \\ Jl. Kapten Muchtar Basri,BA No. 03 Medan Telp. (061) 6622400 ex. 12 Kode pos 20238 \\ e-mail: suryahardi@gmail.com
}

\begin{abstract}
Abstrak - Sistem proteksi berfungsi untuk melindungi peralatan dari kerusakan pada saat terjadinya gangguan serta melokalisir gangguan agar tidak meluas. Dengan sistem proteksi yang baik, maka kerugian yang tidak diinginkan bisa dihindarkan, terutama pada peralatan vital seperti pada generator dan transformator Salah satu peralatan yang berperan dalam sistem proteksi adalah rele proteksi overall diferensial yang digunakan untuk melindungi generator dan transformator.Rele ini melindungi generator dan transformator dari gangguan-gangguan internal seperti hubung singkat antar fasa, hubung singkat dari fasa ke tanah, maupun hubung singkat antar belitan. Rele ini bekerja berdasarkan setting arus dan waktu operasi yang sudah ditentukan sehingga bisa bekerja dengan cepat dan tepat sasaran.Rele bekerja dengan membandingkan arus yang masuk dan keluar. Rele akan mendeteksi adanya gangguan dan memerintahkan pemutus tenaga (PMT) untuk membuka (trip). Sistem proteksi yang baik ditunjang oleh setting yang tepat pada rele diferensial guna mencegah terjadinya kegagalan proteksi dan meningkatkan kehandalan dari system.Penelitian ini bertujuan menganalisa kinerja rele overall diferensial dan mensetting rele overall diferensial pada generator dan transformator.Metode yang digunakan untuk menentukan setting rele diferensial yaitu dengan mencari data sekunder di PT PLN (PERSERO) dan mencari referensi jurnal yang sesuai dengan penelitian yang dilakukan.
\end{abstract}

Kata kunci : Sistem Proteksi, Rele Diferensial, Rele Overall Diferensial dan Setting Rele

\begin{abstract}
Protection system functions to protect equipment from damage when interference occurs and to localize the interference so it does not spread. With a good protection system, then unwanted losses can be avoided, especially on vital equipment such as generators and transformers One of the equipment that plays a role in the protection system is differential overalls protection relays that are used to protect generators and transformers. These cables protect generators and transformers from internal disturbances such as short circuit between phases, short circuit from phase to ground, or short circuit between turns. This relay works based on the current setting and operating time specified so that it can work quickly and precisely on target. incoming and outgoing. Rele will detect interference and instruct the power breaker (PMT) to open (trip). A good protection system is supported by the right settings on the differential relay to prevent protection failure and increase the reliability of the system. This research aims to analyze the performance of the differential overalls and the setting of the differential overalls on the generator and transformer. The method used to determine the differential relay settings is by looking for secondary data at PT PLN (PERSERO) and looking for journal references that are consistent with the research conducted.
\end{abstract}

Keywords : $\quad$ Protection System, Differential Relays, Differential Overall Relays and Rele Settings

\section{PENDAHULUAN}

Pembangkit mempunyai dua proses penting yaitu proses perubahan sumber energi listrik dan proses perubahan tegangan menjadi tegangan lebih tinggi. Pada dua proses ini peralatan penting yang digunakan adalah generator dan transformator step-up. Oleh karena itu kedua peralatan ini harus dilindungi dengan baik oleh rele proteksi.

Salah satu peralatan yang berperan dalam sistem proteksi adalah rele proteksi diferensial yang digunakan untuk melindungi

transformator.Rele ini melindungi generator dan transformator dari gangguangangguan internal seperti hubung singkat antar fasa, hubung singkat dari fasa ke tanah, maupun hubung singkat antar belitan.Rele ini bekerja berdasarkan setting arus dan waktu operasi yang sudah ditentukan sehingga bisa bekerja dengan cepat dan tepat sasaran.Selain itu, rele ini dilengkapi dengan penahan gangguan eksternal dan harmonisa agar tehindar dari salah kerja.Karena pentingnya rele overall diferensial dalam mengamankan generator 
dan transformator, maka rele overall diferensial harus dapat diandalkan dari gangguan- gangguan yang mungkin timbul.

Penggunaan rele overall differential mempunyai keunggulan dibandingkan jenis rele lain. Sehingga untuk meningkatkan keandalan dan kontinuitas pelayanan pengoperasian sistem pembangkit memerlukan suatu peralatan pengaman atau sistem proteksi untuk mencegah terjadinya gangguan yang menganggu sistem. Sistem proteksi merupakan komponen penting untuk menjaga kelangsungan dan keandalan penyaluran energi listrik.Sistem proteksi berfungsi untuk melindungi peralatan dari kerusakan pada saat terjadinya gangguan serta meminimalisir gangguan agar tidak meluas.Dengan sistem proteksi yang baik, maka kerugian yang tidak diinginkan bisa dihindarkan, terutama pada peralatan vital seperti pada generator dan transformator.

Salah satu peralatan yang berperan dalam sistem proteksi adalah rele proteksi diferensial yang digunakan untuk melindungi generator dan transformator.Rele ini melindungi generator dan transformator dari gangguangangguan internal seperti hubung singkat antar fasa atau hubung singkat dari fasa ke tanah.Rele ini bekerja berdasarkan setting arus dan waktu operasi yang sudah ditentukan sehingga bisa bekerja dengan cepat dan tepat sasaran.

Salah satu jenis rele diferensial adalah Rele Overall Differential. Penggunaan rele overall differential mempunyai keunggulan dibandingkan jenis rele diferensial lain. Ini dikarenakan rele overall differential mempunyai 3 input arus dari sisi generator, transformator generator dan trafo pemakaian sendiri.Rele ini mengamankan keseimbangan arus dari tiga sisi.Sehingga rele ini dapat mengamankan generator dan transformator secara langsung.

Berdasarkan uraian diatas maka judul tugas akhir ini akan membahas tentang "Analisis Kerja Rele Overall Differential pada Generator Dan Transformator PLTG Paya Pasir PT. PLN (Persero)" yang dilakukan untuk mengetahui prinsip kerja rele overall diferensial sebagai proteksi pada generator dan transformator, serta umtuk mengetahui settingan dari rele diferensial pada generator dan transformator dalam memproteksi gangguan.

\section{TINJAUAN PUSTAKA}

\section{Pembangkit Listrik Tenaga Gas (PLTG)}

PLTG (Pembangkit listrik tenaga gas) merupakan pembangkit listrik yang memanfaatkan gas untuk memutar turbin dan generator. Turbin dan generator adalah dua benda dengan satu poros yang sama. Jadi, jika turbin berputar, secara otomatis generator pu ikut berputar. Dan jika generator berputar, maka generator akan menghasilkan beda potensial pada medan magnetnya yang akan menghasilkan energi listrik. PLTG, secara prinsip hampir sama dengan PLTU. Hanya saja uapnya diganti dengan gas. Karena karakteristik uap dan gas secara umum berbeda, maka akan ada beberapa prinsip dasar yang berbeda antara turbin uap dan turbin gas. Selain itu, gas yang dipakai dalam PLTG bisa dibilang lebih mudah untuk disiapkan daripada uap, sehingga sebuah PLTG bisa mulai berproduksi dari keadaan "dingin" dalam hitungan menit, sebut saja sekitar 10 menit sampai 30 menit, jauh lebih cepat dari apa yang bisa dilakukan oleh sebuah PLTU.

\section{Generator}

Generator adalah suatu sistem yang menghasilkan tenaga listrik dengan masukan tenaga mekanik . Jadi disini generator berfungsi untukmengubah tenaga mekanik menjadi tenaga listrik yang mempunyai prinsip kerja sebagai berikut:bilamana rotor diputar maka belitan kawatnya akan memotong gayagaya magnit pada kutub magnit, sehingga terjadi perbedaan tegangan, dengan dasar inilah timbullah arus listrik, arus melalui kabel/kawat yang ke dua ujungnya dihubungkan dengan cincin geser. Pada cincincincin tersebut menggeser sikatsikat, sebagai terminal penghubung keluar.

\section{Transformator}

Transformator atau lebih dikenal dengan nama "transformer" atau "trafo" sejatinya adalah suatu peralatan listrik yang mengubah daya listrik AC pada satu level tegangan yang satu ke level tegangan berdasarkan prinsip induksi elektromagnetik tanpa merubah frekuensinya. Tranformator biasa digunakan untuk mentransformasikan tegangan (menaikkan atau menurunkan tegangan AC).Selain itu, transformator juga dapat digunakan untuk sampling 
tegangan, sampling arus, dan juga mentransformasi impedansi.

\section{Proteksi Generator}

Proteksi sistem tenaga listrik adalah sistem proteksi yang dipasang pada peralatanperalatan listrik suatu sistem tenaga listrik, misalnya generator, transformator, jaringan dan lain-lain terhadap kondisi abnormal operasi sistem itu sendiri. Kondisi abnormal itu dapat berupa antara lain: hubung singkat, tegangan lebih, beban lebih, frekuensi sistem rendah, asinkron.

\section{Proteksi Transformator}

Rele pengaman atau sistem proteksi adalah susunan piranti, baik elektronik, magnetic maupun mekanik yang direncanakan untuk mendeteksi suatu kondisi ketidaknormalan pada peralatan listrik yang membahayakan atau tidak diinginkan. Jika bahaya itu muncul maka rele pengaman akan secara otomatis memberikan sinyal atau perintah untuk membuka pemutus tenaga (circuit breaker) agar bagian yang terganggu dapat dipisahkan dari sistem yang normal.

Perhitungan matematis berupa perhitungan arus nominal dan arus rating untuk menentukan rasio CT terpasang pada trafo daya tersebut. Kemudian menghitung besar error mismatch dan menghitung parameter rele berupa arus diferensial, arus restrain (penahan), arus slope dan arus setting rele diferensial. Setelah itu akan dilakukan perhitungan arus yang di keluarkan CT pada saat gangguan dan pengarung terhadap rele diferensial.

\section{Arus rating}

Untuk menghitung rasio CT, terlebih dahulu menghitung arus rating. Arus rating berfungsi sebagai batas pemilihan rasio CT. Perhitungan arus rating menggunakan rumus :

Irating $=$ Inominal Dimana:

Inominal $=\mathrm{S} /(\sqrt{ } 3 \times \mathrm{V})$

In = Arus Nominal (A)

$\mathrm{S}=$ Daya tersalur (MVA)

$\mathrm{V}=$ Tegangan pada sisi primer dan sekunder (KV).
In atau arus nominal merupakan arus yang mengalir pada masing-masing jaringan (tegangan tinggi dan tegangan rendah).

\section{Error mismatch}

Error mismatch merupakan kesalahan dalam membaca perbedaan arus dan tegangan di sisi primer dan sekunder transformator serta pergeseran fasa di trafo tersebut. Menghitung besarnya arus mismatch yaitu dengan cara membandingkan rasio $\mathrm{CT}$ ideal dengan $\mathrm{CT}$ yang ada di pasaran, dengan ketentuan error tidak boleh melebihi $5 \%$ dari rasio CT yang dipilih. Perhitungan besarnya mismatch menggunakan rumus :

Error Mismatch $=(\mathrm{CT}$ Ideal $) /(\mathrm{CT}$ Terpasang )

Dimana :

$(\mathrm{CT} 2) /(\mathrm{CT} 1)=\mathrm{V} 1 / \mathrm{V} 2 \mathrm{CT}($ Ideal $)$

$=$ trafo arus ideal

$\mathrm{V} 1=$ tegangan sisi tinggi

$\mathrm{V} 2$ = tegangan sisi rendah

Arus sekunder CT

Arus sekunder CT merupakan arus yang di keluarkan CT.

Isekunder $=1 /($ rasio $\mathrm{CT}) \times \mathrm{I} n$

Arus diferensial

Arus diferensial merupakan arus selisih antara arus sekunder CT sisi tegangan tinggi dan sisi tegangan rendah.

Rumus untuk menentukan arus diferensial yaitu:

$$
\text { Idif }=I 2-I 1
$$

Dimana:

$$
\begin{aligned}
& \text { Idif = Arus Diferensial } \\
& \text { I1 = Arus Sekunder CT } 1 \\
& \text { I2 = Arus Sekunder CT2 }
\end{aligned}
$$

Arus restrain (penahan)

Arus restrain diperoleh dengan cara menjumlahkan arus sekunder CT1 dan CT2 kemudian dibagi 2 . 
Rumus yang digunakan untuk menghitung arus restrain yaitu :

Dimana:

$$
\mathrm{Ir}=\mathrm{I}_{-}\left(1+\mathrm{I} \_2\right) / 2
$$

$$
\begin{aligned}
& \mathrm{Ir}=\text { Arus penahan }(\mathrm{A}) \\
& \mathrm{I} 1=\text { Arus sekunder CT } 1 \text { (A) } \\
& \mathrm{I} 2=\text { Arus sekunder CT2 (A) }
\end{aligned}
$$

Percent Slope (setting kecuraman)

Slope didapat dengan cara membagi antara arus diferensial dengan arus restrain. Slope 1 akan menentukan arus diferensial dan arus restrain pada saat kondisi normal dan memastikan sensitifitas rele pada saat gangguan internal dengan arus gangguan yang kecil, sedangkan slope 2 berguna supaya rele diferensial tidak bekerja oleh gangguan eksternal dengan arus gangguan yang besar sehingga salah satu CT mengalami saturasi.

Rumus yang digunakan untuk mencari $\%$ slope 1 dan $\%$ slope 2 yaitu :

$$
\begin{aligned}
& \text { Slope } 1=\mathrm{Id} / \operatorname{Ir} \times 100 \% \\
& \text { Slope2 }=(\mathrm{Id} / \operatorname{Ir} \times 2) \times 100 \%
\end{aligned}
$$

Dimana :

Slope 1 : setting kecuraman 1

Slope2 : setting kecuraman 2

Id : Arus Diferensial (A)

Ir : Arus Restrain (A)

Arus setting (Iset)

Arus setting didapat dengan mengalikan antara slope dan arus restrain. Arus setting inilah yang nanti akan dibandingkan dengan arus diferensial.

Rumus matematis Isetting :

$$
\text { Iset }=\% \text { slope } \times \text { Irestrain }
$$
Dimana :

$$
\text { Iset : Arus Setting }
$$$$
\% \text { slope : Setting Kecuraman (\%) }
$$

\section{METODE}

Tempat Penelitian

Lokasi penelitian dilakukan di Laboratorium Universitas Muhammadiyah Data Penelitian

\begin{tabular}{|c|c|c|}
\hline \multirow[t]{19}{*}{ l.Generator } & Pabrikan & $\begin{array}{l}\text { Nanjing Turbine \& } \\
\text { Electric Machinery } \\
\text { (Group) CO., LDT }\end{array}$ \\
\hline & Daya & $42 \mathrm{MW}(52,5 \mathrm{MVA})$ \\
\hline & Tipe & QFR-42-2 \\
\hline & $\mathrm{T}_{\mathrm{L}}=\mathrm{T}_{\mathrm{H}}$ & 2,9 \\
\hline & Ratio hubung singkat & 0,5 \\
\hline & Putaran(r/min) & 3000 \\
\hline & Jumlah Kutub & 2 \\
\hline & Frekuensi $(\mathrm{Hz})$ & 50 \\
\hline & Tegangan Stator $(\mathrm{V})$ & 10500 \\
\hline & Arus Stator (A) & 2886,8 \\
\hline & Ratio kedua CT & $15000 \mathrm{~A} / 5 \mathrm{~A}$ \\
\hline & PTRatio & $10500 \mathrm{~V} / 100 \mathrm{~V}$ \\
\hline & Power Faktor & 0,8 \\
\hline & Hubungan & $\mathrm{Y}$ \\
\hline & $\mathrm{X}_{\mathrm{d}}$ & $0,6 \mathrm{pll}$ \\
\hline & $\mathrm{X}_{\mathrm{I}}$ & $12 \%$ \\
\hline & $\mathrm{X}_{\text {sititem }}$ & $\mathrm{J} 0,106$ \\
\hline & Tegangan Eksitasi (V) & 184 \\
\hline & Arus Eksitasi (A) & 823 \\
\hline
\end{tabular}

Data penelitian yang digunakan dalam penelitian ini diperoleh dari PT PLN (PERSERO) GI Paya Pasir, pada unit 7, yang terdiri dari generator, transformator, dan rele overall diferensial yaitu :

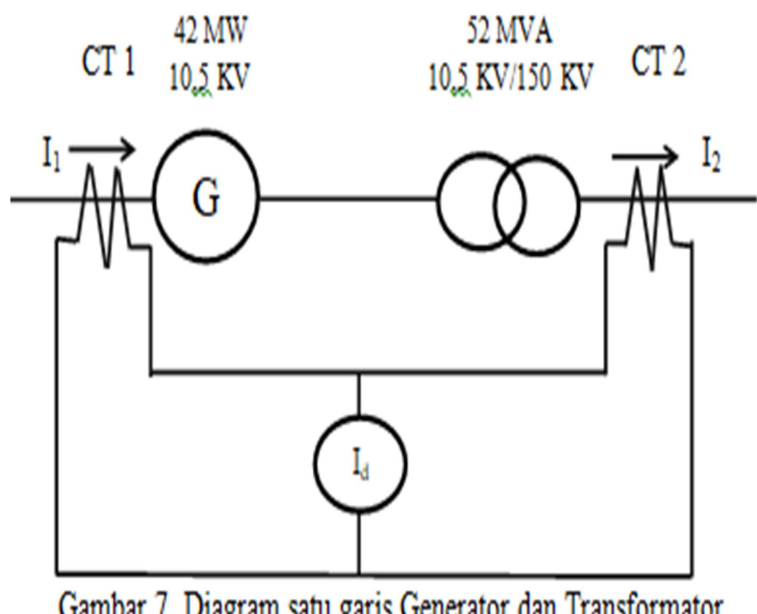

a.Data spesifikasi generator unit 7

Tabel. 1. Data spesifikasi generator unit 7 
6.Data Transformator unit 7

\begin{tabular}{|l|l|l|}
\hline $\begin{array}{c}\text { 2.Tranformator } \\
\text { Utama }\end{array}$ & Daya & $52 \mathrm{MVA}$ \\
\cline { 2 - 3 } & Pendingin & ONAN \\
\cline { 2 - 3 } & Rasio Elektrikal & $10.5 \mathrm{kV} / 150 \mathrm{kV}$ \\
\hline 3.Transformator & Daya & $500 \mathrm{~kW}$ \\
\hline Pembantu & Pendingin & $0 \mathrm{NAF}$ \\
\cline { 2 - 3 } & Rasio Elektrikal & $10,5 \mathrm{kV} / 400 \mathrm{~V}$ \\
\cline { 2 - 3 } & & \\
\cline { 2 - 3 } & Daya & $500 \mathrm{~kW}$ \\
\cline { 2 - 3 } & Pendingin & $0 \mathrm{NAF}$ \\
\cline { 2 - 3 } & Rasio Elektrikal & $20 \mathrm{kV} / 400 \mathrm{~V}$ \\
\cline { 2 - 3 } & & \\
\cline { 2 - 3 } & Daya & $630 \mathrm{~kW}$ \\
\cline { 2 - 3 } & Pendingin & $0 \mathrm{NAF}$ \\
\cline { 2 - 3 } & Rasio Elektrikal & $20 \mathrm{kV} / 400 \mathrm{~V}$ \\
\hline
\end{tabular}

Tabel 2. Data Transformator unit 7

\section{c. Data sele olerall diferensial unit ?}

\begin{tabular}{|c|c|c|c|}
\hline \multirow{2}{*}{\multicolumn{2}{|c|}{$\begin{array}{l}\text { Type } \\
\text { Style } \\
\text { Number }\end{array}$}} & \multicolumn{2}{|l|}{ TAG-2 } \\
\hline & & PY289 & PY340 \\
\hline \multirow{3}{*}{ CTCircuit } & Rated frequency & $50 \mathrm{~Hz}$ & $60 \mathrm{~Hz}$ \\
\hline & Rated current & \multicolumn{2}{|l|}{ 5AAC } \\
\hline & Rated busden & \multicolumn{2}{|l|}{$\begin{array}{l}\text { 5VA orless } \\
\text { MGnimum }\end{array}$} \\
\hline & & \multicolumn{2}{|l|}{$\begin{array}{l}\text { MGrininum } \\
\text { operating value: } \\
0,4 \mathrm{~A} \text { fixed }\end{array}$} \\
\hline \multicolumn{2}{|c|}{$\begin{array}{l}\text { Operating } \\
\text { characterisit }\end{array}$} & \multicolumn{2}{|l|}{$\begin{array}{l}\text { Operating ratio } \\
\text { near aned vahe } \\
10 \% \text { slope }\end{array}$} \\
\hline & & \multicolumn{2}{|l|}{$\begin{array}{l}\text { Variable ata: } \\
\text { Above rated tahos }\end{array}$} \\
\hline \multirow{3}{*}{$\begin{array}{l}\text { Control } \\
\text { ciscuit }\end{array}$} & Voltage & \multicolumn{2}{|l|}{$\begin{array}{l}\text { 110VDC, } \\
\text { allowable } \\
\text { variation range - } \\
20 \% \text { +30\% }\end{array}$} \\
\hline & Burden & \multicolumn{2}{|l|}{601 orless } \\
\hline & Ext.Resistor & \multicolumn{2}{|l|}{$\begin{array}{l}\text { Paralel conneconon } \\
\text { of three } 500 \text { ohhm } \\
\text { resistors (80 W } \\
\text { rating) }\end{array}$} \\
\hline \multirow{4}{*}{$\begin{array}{l}\text { Contact } \\
\text { capacity }\end{array}$} & & \multicolumn{2}{|l|}{$\begin{array}{l}\text { Opening } 110 \\
\operatorname{VDC} 03.3 \text { (19ss } \\
\text { than L R } 40 \text { ms }\end{array}$} \\
\hline & Trip ciscuit & \multicolumn{2}{|l|}{$\begin{array}{l}\text { Cosing } 110 \\
\text { VDC } 15 \mathrm{~A} \\
\text { (sesistive load) }\end{array}$} \\
\hline & & \multicolumn{2}{|l|}{$\begin{array}{l}\text { Opening } 110 \\
\text { VDCO. A } \\
\text { (essistive bade) }\end{array}$} \\
\hline & Alamm circuit & \multicolumn{2}{|l|}{$\begin{array}{l}\text { Cosing } 110 \\
\text { VDC } \mathrm{A} \\
\text { (esistive baso) }\end{array}$} \\
\hline \multicolumn{2}{|l|}{ Case } & \multicolumn{2}{|l|}{ TypeD-D5 } \\
\hline Weight & \begin{tabular}{|l} 
Relay unit only \\
With case
\end{tabular} & \multicolumn{2}{|l|}{$\frac{100 \mathrm{Kg}}{145 \mathrm{Kg}}$} \\
\hline
\end{tabular}

Tabel 3. Data fele over ail diferensial unit ?

\subsection{Diagram Alir Peneliian}

Berikut adalah diagram alir dari proses metodologi penelitian:

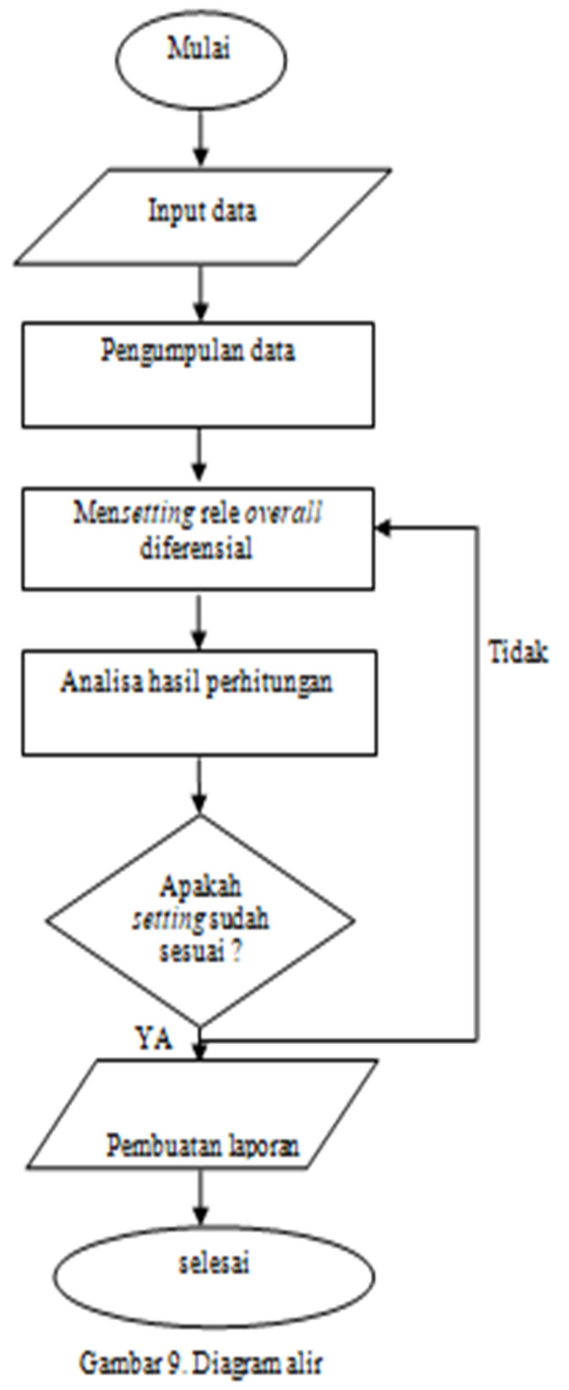

\section{HASIL DAN PEMBAHASAN}

Perhitung berupa hitungan arus rating dan arus nominal yang digunakan untuk menentukan rasio CT pada trafo tersebut, kemudian menghitung arus sekunder CT, Arus defferensial, arus restrain, percent slope, arus setting rele differensial dan gangguan yang ada pada transformator tenaga.

$$
I_{\text {rating }}=I_{\text {nominal }}
$$

Dimana:

$$
I_{\text {nominal }}=\frac{S}{\sqrt{3} \times V_{L-L}}
$$


Surya Hardi, Muhammad Adam, Io Arisandy: ANALISIS KERJA RELE OVERALL

Arus nominal tegangan tinggi 150 Kv, dengan daya tersalurkan sebesar 52 $\mathrm{MVA}$ :

$$
\begin{aligned}
& I_{n}=\frac{52.000 .000}{\sqrt{3} \times 150.000} \\
& I_{n}=200,15 \mathrm{~A}
\end{aligned}
$$

Arus nominal tegangan rendah 10,5 $\mathrm{KV}$, dengan daya tersalurkan sebesar 52 MVA:

$$
\begin{aligned}
& I_{n}=\frac{52.000 .000}{\sqrt{3} \times 10.500} \\
& I_{n}=1364,65 \mathrm{~A} \\
& I_{\text {rating untuk tegangan tinggi } 150}
\end{aligned}
$$
$\mathrm{KV}$, dengan arus nominal sebesar 200,15 A:

$$
\begin{aligned}
I_{\text {rat }} & =100 \% \times 200,15 \\
I_{\text {rat }} & =220,165 \mathrm{~A}
\end{aligned}
$$

$I_{\text {rating }}$ untuk tegangan rendah 10,5 $\mathrm{KV}$, dengan arus nominal sebesar 1364,165 A:

$$
\begin{aligned}
I_{\text {rat }} & =100 \% \times 1364,65 \\
I_{\text {rat }} & =1501,115 \mathrm{~A}
\end{aligned}
$$

Arus setting (Iset)

Arus setting didapat dengan mengalikan antara slope dan arus restrain. Arus setting inilah yang nanti akan dibandingkan dengan arus diferensial.

Rumus matematis Isetting :

Iset $=\%$ slope $\times$ Irestrain

Dimana :

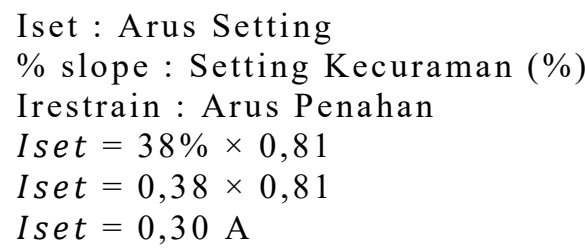

Arus setting yang diperoleh dari hasil perhitungan adalah $0,30 \mathrm{~A}$, setting yang dibuat adalah 0,3 A atau $30 \%$ dengan pertimbangan yaitu : kesalahan sadapan $(10 \%)$, kesalahan CT $(10 \%)$, mismatch $(4 \%)$, arus eksitasi $(1 \%)$ dan faktor keamanan $(5 \%)$.
Mensetting Rele Overall Differensial Pada Generator sisi CT:

Arus Nominal Generator di kedua

$\mathrm{I}_{1 \& 2}=\frac{M V A}{\sqrt{3} \times K V}=\frac{42000000}{\sqrt{3} \times 10.500}=11823 \mathrm{~A}$

Perhitungan Missmatch pada Generator Karena CT pada kedua sisi generator dipasang secara delta maka perhitungan Arus sekunder pada CT kedua sisi generator adalah sebagai berikut:

$\mathrm{I}_{1 \& 2}=\frac{I_{\text {nominal }}}{\text { ratio } C T}=\frac{11823}{15000 / 5}=3,941 \mathrm{~A}$

Selanjutnya menghitung Ratio Trafo Arus Relay yaitu dengan cara :

$$
\begin{aligned}
& \mathrm{I}_{\mathrm{F} 1 \& 2}=\mathrm{I}_{1 \& 2} \times \sqrt{3} \\
& =3,941 \times \sqrt{3} \\
& =6,826012233 \mathrm{~A} \\
& \mathrm{~S}=\frac{I_{F 2}}{I_{F 1}}=\frac{6,826012233}{6,826012233}=1
\end{aligned}
$$

Dari nilai $\mathrm{S}=1$ dapat dilihat dari table ratio trafo didapat nilai $\frac{T_{L}}{T_{H}}=\frac{2,9}{2,9}$, maka dari itu bisa dihitung nilai Missmatch:

$$
\begin{aligned}
\mathrm{M} & =\left(\frac{\frac{I_{f 1}}{I_{f 2}}-\frac{T_{L}}{T_{H}}}{\frac{T_{L}}{T_{H}}}\right) \times 100 \% \\
& =\left(\frac{\frac{6,826012233}{6,826012233}-\frac{2,9}{2,9}}{\frac{2,9}{2,9}}\right) \times 100 \% \\
& =0 \%
\end{aligned}
$$

Karena ratio kedua CT bagian atas dan bawah generator sama, maka menghasilkan nilai Missmatch sebesar 0\% Arus di Rele Differensial pada saat beban penuh

$$
\begin{aligned}
& \mathrm{I}_{\mathrm{d}}=\left|I_{1}\right|-\left|I_{2}\right| \\
& =|6,826012233-6,826012233| \\
& =0 \mathrm{~A} \\
& \begin{aligned}
\mathrm{I}_{\text {r(restrain })} & =\frac{I_{1}+I_{2}}{2} \\
& =\frac{6,826012233+6,826012233}{2} \\
& =6,826012233 \mathrm{~A}
\end{aligned}
\end{aligned}
$$


Setting Slope

$$
\begin{aligned}
\text { Slope } & =\frac{I_{d}}{I_{r}} \times 100 \% \\
& =\frac{0}{6,826012233} \times 100 \% \\
& =0 \%
\end{aligned}
$$

Setting Rele Differensial Minimum Setting = Kesalahan Generator $(\%)+$ Nilai Missmatch (\%) + Error CT (\%) + Toleransi $(\%)+$ Slope $(\%)$ Minimum Setting $=$ $5 \%+0 \%+5 \%+5 \%+0 \%$ Minimum setting $=$ $15 \%$ Oleh sebab itu dipilih setting $15 \%$ untuk rele differensial.

\section{KeSIMPULAN}

Berdasarkan dari penelitian yang dilakukan maka dapat diperoleh beberapa kesimpulan yaitu Rele Overall diferensial adalah salah satu jenis peralatan proteksi yang dapat digunakan untuk melindungi Generator sekaligus Transformator dari gangguan-gangguan yang bersifat internal. Pada transformator arus rating didapat dengan dengan cara menghitung arus nominal pada transformator daya. Arus rating nantinya akan digunakan untuk menentukan rasio CT yang terpasang pada trafo daya. Rele diferensial akan bekerja apabila nilai arus diferensial melebihi arus setting dan sebaliknya. Batas arus nominal yang diperbolehkan mengalir pada trafo daya sisi tegangan rendah adalah $3.780 \mathrm{~A}$, apabila melebihi nilai arus nominal yang diizinkan maka rele diferensial akan mendeteksi adanya gangguan dan mengintruksikan PMT untuk memutuskan (trip). Arus setting yang didapat dari hasil pehitungan yaitu 0,3 A dan diharapan dengan setting tersebut sistem proteksi transformator dapat bekerja dengan optimal. Arus nominal pada generator yaitu sebesar 11823 A. ratio kedua CT bagian atas dan bawah generator sama, maka menghasilkan nilai Missmatch sebesar $0 \%$. Setting Rele Differensial Minimum Setting $=$ Kesalahan Generator $(\%)+$ Nilai Missmatch (\%) + Error CT (\%) + Toleransi $(\%)+$ Slope $(\%)$ Minimum Setting = $5 \%+0 \%+5 \%+5 \%+0 \%$ Minimum setting $=$ $15 \%$ Oleh sebab itu dipilih setting $15 \%$ untuk rele differensial rele differensial untuk gangguan dalam generator didapat minimum setting $15 \%$.

Tentunya penulis menyadari bahwa terdapat banyak kekurangan dalam penelitian ini.Salah satunya adalah dengan tidak menggunakan simulasi, Metode simulasi dapat dijadikan salah satu solusi melakukan pengecekan rutin pada rele diferensial.Karena pengecekan rutin tidak dapat dilakukan saat generator dalam kondisi hidup.

\section{DAFTAR PUSTAKA}

[1] Anditama NP., T. Haryono, Suharyanto. 2010. Jurnal Penelitian Teknik Elektro Vol. 3 No. 4. Yogyakarta : Universitas Gajah Mada.

[2] Syahrial, Anaa Istimaroh, Nasrun Hariyanto. 2013. Penentuan Setting Rele Arus Lebih Generator dan Rele Diferensial Transformator Unit 4 PLTA Cirata II. Bandung : Institut Teknologi Nasional (ITENAS).

[3] Oktavia Fitriyani, Maria., Mochammad Facta, dan Juningtyastuti. 2015. Evaluasi Setting Relay Proteksi Generator Dan Trafo Generator Di Pltgu Tambak Lorok Blok 1. Semarang : Universitas Diponegoro.

[4] Wahyudin SN, Retno Aita Diantari, Teuku Mardhi Rahmatullah. 2017. Analisa Proteksi Differensial Pada Generator Di Pltu Suralaya. Jakarta : Sekolah Tinggi Teknik.

[5] Catur Pamungkas, Ari., Juningtyastuti, dan Agung Nugroho. 2015. Analisis Koordinasi Dan Setting Rele Proteksi Generator Dan Trafo Step Up Di Pltu Tanjung Jati B Unit 1. Semarang : Universitas Diponegoro.

[6] Yahdian, Uffan., Juningtyastuti, dan Karnoto. 2017. Analisis Koordinasi Proteksi Generetor Dan Trafo Generator Pada Pltgu Tambak Lorok Blok 2 Menggunakan Software Etap 12.6.0. Semarang : Universitas Diponegoro.

[7] Prasetijo, Hari., Firman Arif Romadona. 2010. Analisis Kerja Rele Overall Differential pada Generator Unit I PLTA Ketenger PT Indonesia Power UBP Mrica. Jawa Tengah : Universitas Jendral Soedirman.

[8] Amin, Nurhani. 2012. Sistem Proteksi Generator Turbin Uap. Jurusan Teknik Elektro Fakultas Teknik Universitas Tadulako, Palu. 
Surya Hardi, Muhammad Adam, Io Arisandy: ANALISIS KERJA RELE OVERALL DIFERENSIAL PADA GENERATOR DAN TRANSFORMATOR PLTG PAYA PASIR PT. PLN PERSERO

[9] M. Suartika., I.G.N. Rudy., I. W. Rinas. 2015. Analisa Setting Relay Pengaman Generator Pltg Di Pt Indonesia Power Ubp Bali Unit Pesanggaran. Bali : Universitas Udayana.
[10] Rahmatullah, Sunil. 2017. Analisa Proteksi Differensial Pada Generator Di Pltu Suralaya. Jakarta : Sekolah Tinggi Teknik. 